\title{
PROFISSIONALISMO, DIFERENÇA E DIVERSIDADE NA ADVOCACIA E NA MAGISTRATURA PAULISTAS*
}

\section{Maria da Glória Bonelli}

\section{Introdução}

O ideário do profissionalismo enfatiza os sentimentos comuns partilhados pelos pares, dando destaque à neutralidade da expertise para suplantar interesses específicos. Essa visão tem orientado es-

* Esta pesquisa contou com o apoio do CNPq e a participação dos seguintes pesquisadores do grupo Sociologia das Profissões no trabalho de campo e nas discussōes dos resultados: Audria Helena de Souza Perez Ozores, Camila de Pieri Benedito, Carolina Barbisan, Dafne Araújo, Fabiana Luci de Oliveira, Juliana Tonche, Gessé Marques Junior, Maria Natália Barboza da Silveira e Rennê Martins Barbalho. A análise do conjunto dos dados é aprofundada no livro Profissionalismo, gênero e diferença nas carreiras jurídicas (no prelo), no qual são enfocados além dos juízes e advogados, os promotores de justiça, os defensores públicos e os procuradores do estado de São Paulo. tudos sobre as identidades dos grupos profissionais, seja nos processos de construção desses valores, seja nas crises identitárias. Este artigo busca na literatura sobre a diferença uma nova abordagem para refletir sobre a vivência profissional em contextos de inclusão de outros percursos sociais, como o das mulheres e da homoafetividade. A preocupação analítica direciona-se, assim, para as possibilidades e os constrangimentos relativos à visibilidade do gênero e da sexualidade no mundo do Direito. A investigação procurou classificar as formas pelas quais a diferença e a diversidade na carreira são percebidas nas sociedades de advogados e na magistratura, dando atenção às hierarquias internas e às estratificaçōes.

$\mathrm{Na}$ introdução são apresentadas as mudanças ocorridas na advocacia e na magistratura paulistas nas últimas décadas, a participação feminina nessas carreiras e a hipótese da pesquisa. O segundo tópico baseia-se na discussão teórica da diferença, 
em vez dos enfoques já tradicionais sobre identidade e relações sociais de gênero na profissão. O terceiro tópico focaliza a nova forma de organização da advocacia e a estratificação da prática privada a partir de dados quantitativos coletados nos sites de duzentas sociedades de advogados em São Paulo. $\mathrm{O}$ quarto tópico analisa as entrevistas qualitativas, apontando as possibilidades e os constrangimentos ligados à diferença entre os (as) profissionais do Direito. $\mathrm{O}$ quinto sistematiza as principais conclusōes da pesquisa.

A advocacia e a magistratura são as duas carreiras jurídicas que primeiro consolidaram o profissionalismo na conquista de autonomia e insulamento profissional no Brasil, resistindo a ingerências políticas de governos que ameaçaram tal independência. Embora tenham tido sucesso nessa empreitada na dimensão nacional, elas sentiram de diversas formas o impacto da internacionalização do mundo do Direito, seja com os mercados jurídicos transnacionais, seja com as agendas globais para a reforma do Judiciário, afetando as práticas e a organização dessas atividades.

A Ordem dos Advogados do Brasil (OAB) conseguiu garantir o predomínio da advocacia como profissão liberal, exercida principalmente em escritórios de pequeno e médio porte até os anos de 1990, mas vários fatores atuaram para diversificar isso. O boom dos cursos superiores de Direito foi um deles, fenômeno que se aprofundou com o crescimento das faculdades privadas como empresas de ensino de terceiro grau. Em 1989, havia quarenta cursos de Direito no estado de São Paulo. Em 1998, eles saltam para 62; em 2006, para 222, e em 2011, para 253, com este estado detendo $21 \%$ dos cursos existentes no Brasil (Consultor Jurídico, 2007; Almeida, 2010; Melo, 2011). O maior acesso ao curso de Direito foi acompanhado da expansão da participação feminina na área, fator que se somou para diversificar as formas de organização da profissão. Em 2012, a seccional da OAB possuía 248.712 inscritos ativos em seus quadros, sendo 134.852 homens e 113.860 mulheres $(45,8 \%) .{ }^{1}$

A efervescência econômica das privatizações de grandes empresas públicas no final do século $\mathrm{XX}$ ampliou muito as especializações jurídicas, em particular no direito empresarial, com os advoga- dos encontrando novas atividades nas áreas de negócios. Escritórios pequenos conseguiram crescer no cenário da globalização econômica, precisando contratar mais advogados e advogadas para cuidar dos interesses jurídicos da clientela corporativa que se expandia, trazendo demandas especializadas, mas também muitas outras de caráter rotineiro e repetitivo.

O contexto internacional também influenciou o cenário brasileiro. Nessas privatizaçôes, por exemplo, os Estados Unidos atuaram diretamente intensificando as transferências de modelos de instituições e a adaptação da cultura jurídica (cf. Nelken e Feest, 2001). Com isso, houve um impacto nas empresas e nos escritórios de advocacia no Brasil, juntando-se ao boom dos cursos de Direito e à participação feminina para diversificar as formas de organização da atividade. O trabalho jurídico foi perdendo as características homogêneas como profissão exercida em escritórios individuais ou escritórios partilhados por colegas. A passagem dessa forma de organização para a das sociedades de advogados, estratificadas internamente entre sócios com ganhos sobre os resultados e associados com remuneração, foi observada em diversos países influenciados pelo modelo norte-americano. Boigeol (2003) descreve processo semelhante na França, acompanhado de resistências da Ordem dos Advogados de Paris, fenômeno que se observou na atuação da $\mathrm{OAB}$ antes da expansão dos cursos superiores em Direito.

No Brasil, a difusão da nova estrutura centrada na divisão social do trabalho, separando os conteúdos tradicionais das novas especializaçôes e o trabalho rotineiro daquele que demanda maior expertise, foi facilitada pela expansão das mulheres na advocacia. Os escritórios solo e de pequeno porte fazem principalmente o atendimento de clientes individuais, e as médias e grandes sociedades de advogados concentram os clientes empresariais. Mais do que a feminização funcionar como um exército de reserva da profissão, como observado em outros países (Schultz e Shaw, 2003), aqui as mulheres foram sendo incorporadas, o que facilitou o processo de estratificação.

A proliferação das sociedades de advogados no âmbito global é resultado da internacionaliza- 
ção da profissão, cada vez mais inserida nas relaçôes de importação e exportação do conhecimento especializado entre países do norte e do sul, com a padronização transnacional de serviços jurídicos. ${ }^{2}$ Nesses grandes escritórios, o profissional domina línguas estrangeiras, em especial o inglês, tem experiência de curso ou estágio no exterior, o que é enfatizado em seu currículo divulgado na página da firma na internet e representa grandes empresas ou escritórios estrangeiros. Algumas dessas sociedades de advogados chegam a ter filiais fora do Brasil. O tipo de prestação jurisdicional também muda, enfatizando-se o atendimento das necessidades em torno dos negócios dos clientes empresariais, o que com frequência dispensa a ida para litigar no Fórum, como costumava ser a prática característica da profissão.

O sucesso desse modelo pode ser observado pelo crescimento do Centro de Estudos das Sociedades de Advogados (Cesa), que articula e representa os interesses de novecentas firmas de advocacia no país.

A feminização da carreira veio ao encontro dessas transformaçōes, reduzindo a resistência às mudanças na forma tradicional de se exercer a advocacia. A intensificação na divisão social do trabalho foi acompanhada da divisão sexual do trabalho, com as mulheres concentrando-se nas áreas tradicionais e nas atividades mais rotineiras e os homens naquelas mais especializadas e inovadoras. Tal fenômeno não foi observado entre juízes e juízas, havendo menor diferenciação entre os gêneros segundo a área de atuação.
A expansão do ingresso feminino na magistratura é significativa, embora seja menor que observada na advocacia. A progressão na carreira apresenta ritmos distintos no tribunal estadual e no federal.

Em 1993, o Tribunal de Justiça de São Paulo (TJSP) contava com 1.372 magistrados, sendo $10 \%$ de mulheres. No início de 2011 tinha 2.418 magistrados, sendo 749 (31\%) mulheres. Promovida para a segunda instância, em 1993 não havia nenhuma mulher; em 2011, treze desembargadoras ocupavam o tribunal. O total de vagas de desembargadores no TJSP é de 360. Quando os dados foram coletados, ${ }^{3} 354$ cargos estavam preenchidos, e a participação feminina correspondia a menos de $4 \%$.

No Poder Judiciário brasileiro, o TJSP foi o primeiro a consolidar um tipo de profissionalismo moldado a uma instituição pública de elite. As garantias da carreira, o ingresso por concurso com a seleção dos pares, a padronização dos critérios de promoção, o controle interno pela corregedoria, a escolha da cúpula do tribunal pelos membros da segunda instância e a demarcação das fronteiras entre política e profissão deram solidez à autonomia da magistratura. Esse tribunal estadual foi organizado em 1873, tendo uma trajetória vitoriosa de lutas por independência judicial. $\mathrm{O}$ mesmo não ocorreu em outras cortes brasileiras, registrando-se episódios de intervenção do Executivo, como a que extinguiu a justiça federal em 1937, a qual foi restabelecida em 1965 sob o regime militar. Embora a magistratura federal tenha um concurso público para ingresso muito competitivo e meritocrático,

Tabela 1

Distribuição dos(as) Magistrados(as) do Tribunal de Justiça de São Paulo e do Tribunal Regional Federal

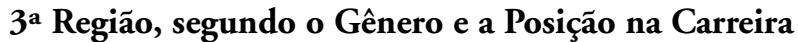

\begin{tabular}{|c|c|c|c|c|c|c|c|c|}
\hline & \multicolumn{4}{|c|}{ TJSP } & \multicolumn{4}{|c|}{ TRF-3 } \\
\hline & \multicolumn{2}{|c|}{ 1a Instância } & \multicolumn{2}{|c|}{ 2a Instância } & \multicolumn{2}{|c|}{$1^{\text {a }}$ Instância } & \multicolumn{2}{|c|}{ 2a Instância } \\
\hline & No & $\%$ & No & $\%$ & No & $\%$ & No & $\%$ \\
\hline Feminino & 736 & 35,7 & 13 & 3,7 & 113 & 37,5 & 19 & 46,3 \\
\hline Masculino & 1328 & 64,3 & 341 & 96,3 & 188 & 62,5 & 22 & 53,7 \\
\hline Total & 2064 & - & 354 & - & 301 & - & 41 & - \\
\hline
\end{tabular}

Fonte: Tabela elaborada a partir do site do TJSP e do TRF-3, 2011. 
até hoje estes tribunais possuem uma autonomia menor para a progressão à segunda instância, que passa pela aprovação do governo federal.

A consolidação do profissionalismo e de seu ideário de neutralidade antes do ingresso feminino na carreira atuou para não dar visibilidade às diferenças e para estratificar a profissão segundo o gênero no tribunal estadual.

O TJSP aprovou o ingresso da primeira juíza na carreira no início dos anos de 1980. Percorrendo os degraus da progressão, só em 2003 duas juízas chegaram ao pleno do tribunal. Já na justiça federal, o ritmo da carreira foi modificado pela Constituição de 1988, que reformulou a estrutura anterior. Extinguiu o Tribunal Federal de Recursos, cuja sede era em Brasília e criou cinco tribunais regionais federais, ampliando as posições a serem preenchidas. A primeira composição que formou o TRF-3, em 1989, foi de catorze desembargadores (78\%) e quatro desembargadoras federais (22\%). Em 2011, essa composição atingia 22 desembargadores $(54 \%)$ e dezenove desembargadoras (46\%).

No TJSP, a hegemonia do profissionalismo precedeu a incorporação da diferença e estratificou acentuadamente o tribunal. No TRF-3, essa hegemonia não estava constituída, suplantando as marcas de gênero na progressão.

Esta pesquisa singulariza os processos de construção do profissionalismo em cada instituição, compreendendo como ele atuou para constranger ou gerar oportunidades às diferenças e como essas marcas sociais foram significadas pelos operadores e operadoras do Direito. Assim, a abordagem distingue-se daquelas que identificam as desigualdades decorrentes do ingresso das mulheres nas carreiras como o teto de vidro (Kay e Hagan, 1995; Thorton, 1996; Junqueira, 1999); como estratégias de fechamento generificado (Davies, 1996; Mossman, 2003; Bolton e Muzio, 2007); e como gap entre os ganhos de homens e mulheres (Menkel-Meadow, 1989; Epstein et al., 1995). O estudo prioriza as formas como advogadas e advogados, juízas e juízes percebem a diferença entre seus pares, no que se refere aos marcadores de gênero e sexualidade.

A hipótese é de que no exercício privado, em especial nas sociedades de advogados, a ideologia da neutralidade do profissionalismo está mais vulnerável à lógica de mercado e à reprodução de estereótipos sobre a diferença. Nesse sentido, predominaria a percepção de que há preconceito em relação a essas marcas, balanceando a interconexão entre profissionalismo, gênero e sexualidade. Por outro lado, a autonomia da magistratura fortaleceria o profissionalismo nessa interseção, ganhando destaque os discursos da inclusão e diversidade.

\section{Das identidades e desigualdades à diferença na profissão}

A literatura sobre a participação das mulheres no mercado profissional problematizou as identidades e as semelhanças partilhadas no mundo do Direito. A condição da prática jurídica foi enfocada a partir das relações sociais de gênero na profissão, reproduzindo no público a ordem privada que acentuava contrastes entre feminino e masculino. Algumas abordagens detiveram-se na análise das desigualdades que acompanharam as advogadas, em termos de mobilidade e remuneração. Outras investigaram a estratificação e a segmentação da carreira.

No Brasil, três estudos sociológicos centram-se nas relações sociais de gênero na advocacia. Junqueira (1999) reporta-se ao estudo de Thornton (1996) sobre o teto de vidro na profissão na Austrália, como também a estudos que focalizam a mesma temática em outros países, para pensar as especificidades e as semelhanças com o caso brasileiro. Bonelli et al. (2008), partindo do conceito de script sexuado (Feuvre e Lapeyere, 2005) de progressão na carreira, analisam o impacto desses estereótipos na profissionalização de uma amostra de 216 jovens advogados e advogadas dos escritórios paulistas. Barbalho (2008) procura identificar como a presença feminina nas carreiras jurídicas no Brasil reflete-se no profissionalismo, e qual a influência dessa participação em carreiras consolidadas, a partir da predominância de uma ortodoxia masculina de fazer e pensar o trabalho.

$\mathrm{Na}$ literatura internacional mais recente, Kay e Gorman (2008) sintetizaram as três perspectivas teóricas que explicam o "gap de gênero" entre os ganhos de advogados e advogadas. Segundo elas: 
A perspectiva do capital humano mostra que as diferenças de gênero na oferta de trabalho (por exemplo, horas de trabalho, interrupçōes na carreira e no regime de trabalho de tempo parcial) relacionadas com a orientação das mulheres para suas famílias são a principal causa das diferenças de ganho baseadas no gênero. A perspectiva estrutural assume que homens e mulheres são encaminhados para (ou eles mesmos selecionam) diferentes lugares estruturais (setores, ambientes de prática, áreas de especialização) e que os lugares masculinos recebem salários mais lucrativos. A perspectiva da discriminação afirma que os empregadores na profissão jurídica se engajam em várias formas de vieses ou discriminação que geralmente só podem ser detectados como efeito residual do gênero sobre a remuneração e/ou uma interação entre o gênero e o capital humano (mulheres e homens recebem diferentes retornos por seus investimentos, por exemplo, em horas trabalhadas, anos de experiência, área de especialização ou treinamento jurídico). Este modelo também enfatiza obstáculos institucionais (ausência de mentores, redes limitadas de apoio, punição pelas horas reduzidas, assédio sexual e discriminaçăo), os quais obstam a capacidade das mulheres de serem bem-sucedidas na advocacia (Epstein et al., 1995, Rhode, 2001), e estereótipos de gênero, incluindo pressupostos sobre o compromisso das mulheres com a carreira, que desfavorecem as mulheres no mercado de trabalho jurídico (Menkel-Meadow, 1989). Vários pesquisadores têm testado essas explicações, com resultados mistos (Kay e Gorman, 2008, p. 313).

Bolton e Muzio (2007) sumariaram os estudos sobre estratificação de gênero na advocacia e sugeriram que há um mecanismo de fechamento generificado interno às profissōes jurídicas, com três padrōes distintos de carreira: a estratificação, a segmentação e a sedimentação. O primeiro ocorre na linha vertical, negando-se às mulheres acesso ao topo da ocupação. O segundo processa-se na linha horizontal, formando guetos de mulheres confinadas a áreas menos valorizadas (direito de família versus direito de negócios); o terceiro dá-se com as profissionais recorrendo ao essencialismo como forma de organizar a identidade de gênero em enclaves numa tentativa de empoderamento.

Em uma perspectiva crítica ao enfoque das relaçōes sociais de gênero, Feenan (2009) problematizou os riscos de reificação dos estereótipos de gênero pelas vertentes teóricas que os analisam. Baseado na proposta de Rackey (2009) de redirecionar o debate para a diferença em vez da essencialização de gênero, nossa abordagem apoia-se na noção de Brah (2006, p. 374), que "se refere à variedade de maneiras como discursos específicos da diferença são constituídos, contestados, reproduzidos e ressignificados". A tipologia sugerida por essa autora é composta da diferença como experiência, como relação social, como subjetividade e como identidade. Para ela, "é útil distinguir a diferença como marcador de distintividade,de nossas 'histórias' coletivas da diferença como experiência pessoal, inscrevendo a biografia individual. Esses conjuntos de 'diferenças' se articulam constantemente, mas não podem ser 'lidas' uma a partir da outra” (Idem, p. 361).

Segundo Brah, a diferença como experiência é aquela inscrita na biografia individual, e aparece como lugar de formação do sujeito, sendo ambos concebidos como processo. Desaparece, pois, a "noção de que essas categorias são entidades unificadas, fixas e já existentes, e não modalidades de múltipla localidade, continuamente marcadas por práticas culturais e políticas cotidianas" (Idem, ibidem). O sujeito da experiência não é um ser pronto a quem as experiências acontecem. A diferença como experiência carrega as contradiçóes da subjetividade e da identidade.

A diferença como relação social refere-se à forma pela qual ela é constituída por discursos sistemáticos de contingência, sejam eles econômicos, políticos ou culturais, e pelas práticas institucionais. Um grupo articula esta diferença ao narrar as experiências históricas coletivas como um passado comum, tal como o legado da escravidão. Elas produzem as condiçôes para as identidades coletivas, para os discursos compartilhados, mas não precisam se concretizar em comunidade.

A diferença como subjetividade é percebida como interioridade, mas o sujeito em processo é 
constituído em e através da experiência "interior" e "exterior". Essa formação da subjetividade é ao mesmo tempo social e subjetiva, "de onde o sujeito é entendido como descentrado e heterogêneo em suas qualidades e dinâmicas. A subjetividade então não é unificada nem fixada, mas fragmentada, constantemente em processo" (Idem, p. 368)

$\mathrm{Na}$ diferença como identidade, ela "pode ser entendida como o próprio processo pelo qual a multiplicidade, a contradição e a instabilidade da subjetividade são características coerentes, contínuas e estáveis; apresentando um núcleo -em constante mudança, mas de qualquer maneira um núcleo - que a qualquer momento é enunciado como o 'eu'” (Idem, p. 371). Para a autora, é problemático falar da identidade de maneira fixa, pois se trata de um processo, sendo mais apropriado referir-se à identificação. A identidade proclamada é uma construção; a identidade coletiva específica é um processo político.

A tipologia proposta por Brah parte da ideia de que não há identificação singular da diferença, nem predomínio de um marcador sobre outro. É a interseção entre os marcadores sociais que dá sentido ao self.

Este estudo procurou captar os discursos sobre a diferença na carreira dos advogados e advogadas, juízes e juízas. O trabalho de campo buscou localizar profissionais que aceitassem participar da pesquisa, por meio de contatos nos fóruns e nos escritórios de advocacia e por indicação de pares. As entrevistas foram realizadas por quatro pesquisadoras e um pesquisador, que se orientaram por um roteiro semiestruturado, obtendo autorização para gravá-las, preservando o anonimato do(a) entrevistado(a). Elas foram realizadas no local de trabalho, com duração variável entre 50 minutos e $2 \mathrm{hs}$. Selecionaram-se mulheres e homens em diferentes momentos da carreira, na capital e no interior do estado. As entrevistas foram transcritas e trabalhadas no programa NVivo 9.

Foram realizadas 52 entrevistas: 24 com advogadas e advogados, 18 com juízes e juízas estaduais e 10 com juízas e juízes federais. Este artigo prioriza a caracterização da advocacia, analisando os dados sobre as sociedades de advogados em São Paulo, as entrevistas com profissionais dos escritó- rios da elite da advocacia na capital (11 milhóes de habitantes) e com advogados(as) dos pequenos escritórios em duas cidades interioranas $(80 \mathrm{mil} \mathrm{e}$ 110 mil habitantes ${ }^{4}$ ). Isso deu visibilidade à grande distância social entre esses dois padrões de prática do Direito.

Nas entrevistas, abordaram-se o perfil e a trajetória profissional, as relações de gênero, a sexualidade de mesmo sexo e a convivência entre os colegas, enfatizando a diferença, a discriminação, a diversidade, a performance e a postura profissional. A caracterização da carreira judicial e os depoimentos de juízas e juízes foram examinados em Bonelli (2011). Apresenta-se aqui uma síntese das conclusões desse estudo para comparar com os discursos de advogados e advogadas.

\section{A expansão das novas formas de organização da advocacia}

Em 2011, havia 385 sociedades de advogados no estado de São Paulo filiadas ao Cesa, das quais 198 possuíam páginas na internet com dados disponíveis para coleta e análise. Elas foram agrupadas em três categorias: pequenas ( 1 a 9 advogados), médias (10 a 49 advogados) e grandes (50 advogados ou mais), resultando em 61 sociedades pequenas, 116 médias e 21 grandes.

Os advogados e advogadas atuantes nessas sociedades foram classificados segundo a posição ocupada. Vários dos sites hierarquizavam seus profissionais, dividindo-os em sócios e associados, mas outros escritórios não apresentavam essa estrutura, referindo-se ao grupo de advogados como "a equipe" da sociedade de advogado. Assim, reproduziu-se tal classificação, preservando a denominação usada no escritório. A estratificação dos escritórios e de seus profissionais configura-se no padrão de organização da carreira hoje, em especial nas sociedades de advogados filiadas ao Cesa. Elas concentram a elite da profissão. Assim, é uma amostra de escritórios cuja autoimagem está associada ao direito empresarial, mesmo que isso se realize na prática de maneiras distintas. Os resultados refletem essa realidade específica que contrasta com a do conjunto da profissão. 
Os dados obtidos para São Paulo referem-se a 4.279 advogados, entre os quais 2.032 mulheres. Havia 1.311 profissionais nos grandes escritórios, 2.544 em escritórios médios e 424 nos pequenos. Como já observado em pesquisa anterior (Bonelli et al., 2008), na condição de sócias, as advogadas são sub-representadas em todos os escritórios (Tabela 2). Mas são nos escritórios menores, organizados na forma tradicional, que a assimetria é maior. Poucas mulheres estão à frente dessa prática jurídica (17\%) nos escritórios filiados ao Cesa.

No trabalho de campo realizado em duas cidades do interior de São Paulo, observa-se uma significativa presença da atuação solo de advogadas. Algumas delas manifestaram a intenção de se associar a outros escritórios, mas encontravam dificuldades, já que a "carteira de clientes" e as redes que dispunham não ajudavam esse ingresso. Nessas localidades, elas obtinham clientela principalmente através do convênio entre OAB-SP e o governo estadual para assistência judiciária a pessoas de baixa renda.

A literatura específica tem encontrado um predomínio da especialização entre os homens, ficando as mulheres confinadas às áreas e atividades mais rotineiras, formando enclaves femininos na profissão. Em pesquisa realizada em 2008, observou-se esse padrão, mas nas informaçōes recolhidas nos sites das sociedades de advogados paulistas isso não se confirmou, o que demonstra uma distinção nessa elite profissional. Entre os sócios, homens e mu- lheres apresentaram a mesma proporção de estudos pós-graduados (61\%), sendo que eles tinham mais formação de mestrado e doutorado strictu senso e elas mais pós-graduação lato senso e MBA, entre outros. Entre os associados e as equipes, há uma redução na proporção de profissionais com formação posterior ao bacharelado, mas a maioria apresenta investimento em estudos de pós-graduação, sendo semelhante para homens (52\%) e mulheres (51\%). $\mathrm{O}$ investimento em educação depois de concluída a graduação é um diferencial para ser sócio, sendo também relevante para compor os quadros profissionais das sociedades de advogados. Nessa amostra, as dificuldades para as advogadas combinarem vida profissional e familiar não responderam por diferenças significativas na realização desses cursos.

Nota-se nessas sociedades o enobrecimento acadêmico, embora a longa formação do doutorado se revele um título escasso e masculino. Tal distinção ganha especial significado na internacionalização, diferenciando os notáveis da massa de advogados que lida com atividades rotineiras. Tal perfil de escolaridade é encontrado nos escritórios vinculados ao Cesa, não podendo ser generalizado para o conjunto da profissão.

A composição de gênero contrasta com os dados obtidos para os grandes escritórios argentinos, que além da proximidade regional apresentam uma proporção semelhante de mulheres na advocacia. Bergoglio (2007) encontrou uma presença femi-

Tabela 2

Distribuição dos(as) Advogados(as) de São Paulo, das Sociedades Filiadas ao Cesa, segundo Gênero, Tamanho do Escritório e Posição Ocupada

\begin{tabular}{llllllllll}
\hline & \multicolumn{9}{c}{ Posição Ocupada } \\
\cline { 2 - 10 } Tamanho & \multicolumn{3}{c}{ Sócios } \\
\cline { 2 - 10 } escritório & Homens & Mulheres & Total (N) & Homens & Mulheres & Total (N) & Homens & Mulheres & Total \\
\hline $\mathbf{1 ~ a ~ 9 ~}$ & $83 \%$ & $17 \%$ & 88 & $48 \%$ & $52 \%$ & 175 & $57 \%$ & $43 \%$ & 161 \\
\hline $\mathbf{1 0}$ a 49 & $71 \%$ & $29 \%$ & 551 & $46 \%$ & $54 \%$ & 1473 & $54 \%$ & $46 \%$ & 520 \\
\hline $\begin{array}{l}\mathbf{5 0} \text { ou } \\
\text { mais }\end{array}$ & $72 \%$ & $28 \%$ & 225 & $44 \%$ & $56 \%$ & 809 & $49 \%$ & $51 \%$ & 277 \\
\hline Total & $72 \%$ & $28 \%$ & 864 & $45 \%$ & $55 \%$ & 2457 & $53 \%$ & $47 \%$ & 958 \\
\hline
\end{tabular}

Fonte: Tabela elaborada a partir do site do Cesa, 2011. 
Tabela 3

Distribuição dos(as) Advogados(as) de São Paulo, das Sociedades Filiadas ao Cesa, segundo Gênero, Escolaridade e Posição Ocupada

\begin{tabular}{|c|c|c|c|c|c|c|c|c|c|}
\hline \multirow[b]{3}{*}{ Escolaridade } & \multicolumn{9}{|c|}{ Posição Ocupada } \\
\hline & \multicolumn{3}{|c|}{ Sócios } & \multicolumn{3}{|c|}{ Associados } & \multicolumn{3}{|c|}{ Equipe } \\
\hline & Homens & Mulheres & Total & Homens & Mulheres & Total & Homens & Mulheres & Total \\
\hline Bacharel & $27 \%$ & $22 \%$ & $25 \%$ & $33 \%$ & $31 \%$ & $32 \%$ & $25 \%$ & $27 \%$ & $26 \%$ \\
\hline Mestre & $17 \%$ & $13 \%$ & $16 \%$ & $10 \%$ & $6 \%$ & $8 \%$ & $13 \%$ & $9 \%$ & $11 \%$ \\
\hline Doutor & $10 \%$ & $3 \%$ & $8 \%$ & $1 \%$ & $0,4 \%$ & $1 \%$ & $5 \%$ & $2 \%$ & $4 \%$ \\
\hline Pós-graduado & $34 \%$ & $45 \%$ & $37 \%$ & $41 \%$ & $46 \%$ & $44 \%$ & $35 \%$ & $37 \%$ & $36 \%$ \\
\hline $\begin{array}{l}\text { Sem } \\
\text { informação }\end{array}$ & $12 \%$ & $17 \%$ & $14 \%$ & $15 \%$ & $17 \%$ & $16 \%$ & $22 \%$ & $24 \%$ & $23 \%$ \\
\hline Total (N) & 625 & 239 & 864 & 1113 & 1344 & 2457 & 509 & 449 & 958 \\
\hline
\end{tabular}

Fonte: Tabela elaborada a partir do site do Cesa, 2011.

nina menor nas sociedades de advogados argentinas do que nas brasileiras, uma participação ainda menor como sócias dos grandes escritórios e como portadoras de cursos de pós-graduação. As desigualdades entre homens e mulheres no caso argentino revelaram-se mais acentuadas.

Recentemente, os estudos na área passaram a observar como a internacionalização do modelo das sociedades de advogados vem repercutindo também na importação e na exportação do padrão de enfrentamento das barreiras à progressão das mulheres na carreira.

Em 2009, um grupo de sócias de grandes escritórios paulistas vinculados ao Cesa organizou em um hotel da cidade de São Paulo um evento com a participação do Committe on Women in the Profession (Comitê da Mulher Advogada), da New York City Bar Association (Ordem dos Advogados de Nova York), para discutir o relatório "Best practices for the hiring, training, retention and advancement of women attorneys" [Boas práticas para a contratação, treinamento, retenção e progressão das mulheres advogadas], divulgado em 2006. Este comitê norte-americano vinha realizando reuniões em diversos países para estimular as advogadas a discutirem tal agenda. $\mathrm{O}$ evento reuniu cerca de 120 mulheres de escritórios paulistas e de advogadas de grandes corporações, constituindo um público de cor branca, em sua maioria jovem. Carrie Cohen, presidente do Comitê, e Marissa Wesely, sócia de um das dez maiores sociedades de advogados da cidade de Nova York, vieram discutir sobre as dificuldade de as advogadas chegarem ao topo da profissão, visto que entram na carreira em proporção semelhante aos homens. O relatório fazia uma análise das razões dessa falta de ascensão e o que poderia ser feito nesse sentido. As palestras e os debates no plenário detiveram-se na forma como o gênero é estigmatizado na prática profissional, principalmente através do estereótipo de que as mulheres são menos comprometidas com o trabalho, priorizando família e filhos. Em contraste com esse pressuposto, as palestrantes apontaram, como motivo de saída da firma, a insatisfação das advogadas norte-americanas com a profissão. As barreiras para se chegar à condição de sócia seriam as dificuldades em articular redes, a falta de mentoras e de representação, a não participação em comitês profissionais e a presença menor em eventos sociais (frequentar happy hours, jantares), além dos constrangimentos em falar sobre dinheiro, cobrar clientes e fazer autopromoção. A pauta de discussão girou em torno do enfretamento a estereótipos negativos do essencialismo de gênero, recorrendo ao lado positivo dessa mesma moeda: como as mulheres acrescentam 
rentabilidade às firmas, transformando a "fraqueza" desorganizada em "força" articulada.

A organização do evento ficou a cargo de uma sociedade de advogados de longa tradição (Pinheiro Neto, 78 sócios e 220 associados, em janeiro de 2012). A iniciativa favoreceu a circulação internacional desse escritório na rede das grandes firmas de advocacia norte-americanas. Para as mulheres presentes, este evento representou mais inclusão do que exposição estigmatizada pelos pares e possibilitou compartilhar referências com outras advogadas, ampliando suas redes, a navegação social e a valorização das habilidades profissionais femininas.

A realização do evento, decorrente de relaçōes de exportação e importação de saberes, aponta como um grupo de advogadas vem percebendo a interseção entre profissionalismo e gênero na chave da diferença como identidade, segundo a tipologia proposta por Brah (2006). Isso, entretanto, não nos permite afirmar que a segmentação generificada na advocacia brasileira caminha para a sedimentação, recorrendo ao essencialismo da identidade de gênero para empoderar enclaves femininos (Bolton e Muzio, 2007). Várias manifestações na reunião abordaram a distância entre as propostas do relatório apresentado e o cotidiano das advogadas nos escritórios paulistas.

\section{Possibilidades e constrangimentos à diferença}

As entrevistas foram realizadas com sócios(as) e associados(as) dos escritórios de elite e com advogadas e advogados vinculados ou não a pequenos escritórios ou em atuação solo, observando-se o contraste entre o perfil profissional e os discursos sobre a diferença na carreira. Entre os 24 advogados entrevistados na pesquisa, 14 eram mulheres. A maioria da amostra estava na faixa etária dos 30 aos 40 anos (62\%), 54\% era casada e apenas uma advogada tinha cônjuge profissional na área do Direito. Já para a ocupação do pai, $25 \%$ eram originários do mundo jurídico. Metade da amostra tinha filhos. Entre os que tinham filhos, havia mais mulheres. Dos entrevistados solteiros, dois informaram ser gays. Os nascidos no Estado de São Paulo eram a ampla maioria (92\%).
Os entrevistados estão divididos entre profissionais atuantes na capital (38\%) e no interior do estado. As sociedades de advogados da capital contrastam com os escritórios menores, em especial das duas localidades estudadas. Uma das sociedades de advogados da capital era pequena, mas altamente especializada, sendo considerada uma "boutique jurídica"s em direito administrativo. Nas grandes e médias sociedades, os entrevistados trabalhavam com clientes empresariais, em mercado de capitais e operaçôes financeiras, nas áreas tributárias, societárias e de contratos, mas também cuidavam dos demais interesses jurídicos desses clientes. No interior, predominam os escritórios menos especializados, fazendo o contencioso na área cível, trabalhista, comercial e penal.

A metade dos profissionais formou-se em $\mathrm{Di}$ reito na década de 1990 , e $37 \%$ concluíram o curso na década de 2000. Três entrevistados eram egressos de universidades públicas contra $21(87 \%)$ em faculdades privadas, sendo dez no interior. Três advogadas haviam concluído outra faculdade. Quanto à especialização ou pós-graduação, 3 mulheres e 2 homens (36\%) possuíam algum tipo de formação.

A percepção da diferença como discriminação na carreira é mais acentuada para os profissionais das sociedades de advogados, do que para os juízes e juízas, que deram ênfase à diversidade como inclusão na carreira.

Entre os advogados no interior, tanto na atuação solo quanto nos pequenos escritórios destaca-se a visão de que a diferença de gênero na carreira decorre da "natureza" de mulheres e homens e de suas respectivas preferências, predominando a explicação da perspectiva do capital humano (Becker, 1964 apud Kay e Gorman, 2008). As advogadas mais jovens sentem que os clientes desconfiam de sua competência, mas atribuem esse fato à idade e não ao gênero, o que também se observou em depoimentos de juízas sobre o início da carreira. Apenas duas advogadas no interior apontaram a existência de preconceito, mas uma delas disse que isso existia nos grandes escritórios e não no interior. A discriminação por causa da homossexualidade foi mais identificada, impondo-se a "lógica do armário" "postura profissional" que torna invisível esta marca. 
$\mathrm{Na}$ análise das entrevistas, a temática que reuniu mais manifestaçóes discursivas foi a do preconceito, registrada na fala de todos os entrevistados(as), demonstrando unanimidade na identificação de que ele existe na carreira e que afeta os profissionais. Os sócios(as) dos escritórios foram mais enfáticos nos relatos sobre a discriminação sutil ou explícita aos marcadores visíveis da diferença sejam de gênero, sexualidade e raça, sejam de classe ou aparência.

Dessa expressiva referência ao preconceito decorrem várias percepções da diferença. As passagens a seguir ilustram os discursos sobre a diferença como relação social e como experiência. Relacionamos os primeiros aos trechos em que o(a) entrevistado(a) narra uma situação social de discriminação vivenciada por outra pessoa. Nas passagens em que o relato é sobre si mesmo, indicando exclusão, associamos à diferença como experiência. Assim, alguns excertos contêm esses dois tipos de percepção.

Tem uns que olham e falam: eu não quero trabalhar com mulher. Esse aí, ele nasceu torto e a gente não vai desentortar entendeu? Não dá. Não dá. [...] Eu acho o pior é aquele que fala: ah tudo bem, eu topo mulher. Mas ele sempre dá um jeito de não promover a mulher. Esse eu acho pior, porque o outro pelo menos é honesto, entendeu? Ele fala: eu não quero, eu não quero ter problema na minha vida. O outro, tem sempre aquele que fala não, não, politicamente correto, ele aceita homem e mulher, mas chega na hora: você está cuidando desse caso? O que você quer fazer da sua vida? Você quer estudar fora, você quer fazer o quê? Você quer ser juiz? E você, quando é que vai ter outro filho? Entendeu? Esse eu acho que é o pior porque esse é fingido [Advogada-sócia, 36-40 anos, casada, com filho].

Agora falando um pouco de raça, eu tenho um amigo da faculdade que é negro, não é mulato, é negro. Ele trabalhou em grandes escritórios, mas eu acho que ele teve um pouco de dificuldade porque além de negro, gordo. Uma coisa que é verdade, o físico do advogado pesa, tem que ser bem cuidado. A gen- te brinca que você vai a um puta escritório assim, você não vê ninguém feio, horroroso, tem um certo,é, isso é uma coisa que a gente conversa [Advogada associada, 21-25 anos, solteira, sem filho].

As complicações são diferentes, eu acho, por exemplo, que a questão da raça é uma coisa que você não tem como esconder, às vezes o preconceito é menos velado, é mais explícito, e às vezes você nem tem a situação do preconceito porque... nem chegou. E às vezes justamente o preconceito e a dificuldade está aí, em nem permitir que se chegue. Eu nunca recebi um currículo de negro pra entrevistar, nunca, nunca, não chegou, nunca. Então isso é um [...]. Então, não acho que as pessoas vão dizer um negro não vai entrar, mas tem uma certa barreira que não é uma porta, se fosse uma porta era mais fácil porque a porta a gente abre. Até porque o ambiente é muito elitizado. Também não é só uma questão de cor da pele não. Não vamos nutrir falsas ilusōes, é assim. Também não estou fazendo juízo de valor de certo e errado, fácil, difícil. Mas o ponto é o seguinte: é um ambiente elitizado sim [Advogada-sócia, 36-40 anos, casada, com filho].

Eu acho que a minha opção sexual sempre me fez dar mais duro, mais duro porque o medo de ser discriminado e tudo mais, você acaba buscando uma proteção para seu sucesso profissional. Se você tem esse sucesso profissional é mais difícil a pessoa sobrepujar isso com você e tal $[\ldots]$.

Eu tenho um amigo que trabalhou aqui comigo na mesma equipe, que na época não sabia, quer dizer, eu não sabia abertamente que ele era gay, ele também não sabia abertamente que eu era gay, mas ele sofreu preconceito aqui mesmo. $\mathrm{Na}$ época ele foi demitido, obviamente não é uma coisa aberta, eu acho que ele foi demitido porque ele era gay. Talvez pelo fato dele ser um pouco mais afeminado, que pode ter originado esse tipo de preconceito, isso é uma coisa que eu realmente vejo 
nas pessoas, eu acho que hoje em dia a opção sexual é muito menos tabu, mas ela é menos tabu com as pessoas que não tem... as marcas visíveis, o que é muito triste. Qual o problema? [Advogado-sócio, 36-40 anos, solteiro, sem filho].

A percepção do preconceito foi menos presente entre juízes e juízas se compararmos às falas de advogados e advogadas. $\mathrm{Na}$ magistratura o tema ocupou o quinto lugar: entre os 28 magistrados, dez não mencionaram questôes de preconceito na profissão.

Há também relatos que negam no percurso profissional a discriminação na carreira, afirmando, ao contrário, haver inclusão e diversidade. $\mathrm{Na}$ passagem a seguir, a diferença é percebida como subjetividade, encapsulada no self, exteriorizando-se principalmente a identificação com a profissão:

É igual, eu acho que a entrada como candidatos estagiários é igual, não tem diferenciação e também não tem preferência, ah vamos contratar homens ou mulheres, pela questão de raça também não, eu acho que não tem essa diferenciação e orientação sexual também não. Obviamente que estou mantendo uma postura profissional, não vejo, não tem problema nenhum, isso na contratação, agora dentro do escritório, eu sou gay, tá, pra deixar registrado aí, eu nunca tive problema nenhum com isso, assim, minha vida particular, é minha vida particular, venho aqui pra trabalhar e ponto final. Eu tenho os meus amigos aqui, que são amigos de trabalho, não são amigos da vida. Muitos amigos daqui sabem, não tem problema nenhum comigo. Eu acho que os sócios de capital, os chefes também sabem, eu nunca falei nada, mas acho que as pessoas acabam percebendo, desconfiando, porque nos eventos sociais, nos casamentos, nas festas eu estou sempre sozinho, e também pela própria postura, tem aquela coisa que o pessoal adora futebol, eu já detesto, então todo mundo já sabe que eu não gosto de futebol, que assunto chato e não sei o quê. Então assim, nunca teve problema com isso. $[. .$.
Não, olha tenho amigos que são sócios de grandes escritórios, são super bem posicionados, outros são advogados seniores, advogados juniores, estagiários, então assim, todos os meus amigos estão muito bem colocados e muito bem-sucedidos, eu não vejo esse problema (Advogado-sócio de renda, ${ }^{6}$ 26-30 anos, solteiro, sem filho].

As próximas duas falas são de um homem e uma mulher, sócios no mesmo escritório no interior. $\mathrm{O}$ primeiro entrevistado reconhece as práticas discriminatórias na carreira e relata uma situação de preconceito dirigida a si, o que ele atribui ao fato de ter contratado um advogado sobre quem paira a suspeita de ser homossexual:

[...] fui indagado por este colega: escuta lá no seu escritório você só contrata esse tipo de pessoa com este comportamento? Por quê? Porque fulano de tal é assim? Não sei, é ? É! Acho que você tá enganado, mas se for, para mim não faz a mínima diferença. Mas cicrano também é? Escuta, o que você tem com isso? Você tá interessado? Ele falou assim: eu tô vendo! Ué, você tá vendo o quê? Eu sou casado, tenho minha mulher, minha opção é bem firme, não preciso provar nada pra você. Aí ele falou: foi mal, você ficou ofendido! Não, não tenho nada com isso, e se eu fosse, qual o problema? Eu te cantei alguma vez? Ele tem que respeitar o cara, ele é profissional, tá exercendo a profissão dele [Advogado-sócio, 36-40 anos, casado, 2 filhos].

A experiência de ser um profissional gay em uma grande sociedade de advogados da capital contrasta com o relato sobre a situação no interior, em que o preconceito é vocalizado nas piadinhas dirigidas também ao sócio que recruta a equipe.

O [nome do advogado] está saindo do armário agora, ele ainda não falou para nós, isso não é problema, a atitude dele tem que ser diferente, o problema dele são os pais, desde a contratação eu já percebi. [...] Não, isso não é problema não, a atitude dele tem que ser diferente, desde que não ofenda ninguém, ele só 
não pode é chegar aqui de Maria Chiquinha etc. etc., porque não condiz com o ambiente, ele tem que se comportar de acordo com o ambiente. Se eu chego num ambiente gls eu não posso ficar assim, né? [fez trejeitos com as mãos], como uma pessoa homossexual chega num ambiente ele tem que respeitar o ambiente onde ele está, um casal que vai num boteco ele não vai ficar se agarrando, se beijando,não vai ficar sentando no colo do outro em público, isso depende da postura da pessoa, não da opção [Advogada-sócia, escritório familiar no interior, 46-50 anos, divorciada, com filho].

Essa manifestação reafirma os estereótipos que desqualificam e subalternizam a sexualidade diferente, mesmo quando a entrevistada afirma não ter preconceito. A preocupação em preservar o escritório do estigma de contratar uma pessoa gay é contrabalanceada pela ênfase na "postura profissional": no caso, um comportamento que não macule com condutas profanas o que há de sagrado no ambiente da profissão.

O segundo assunto que teve mais referências nos relatos foi a performance profissional. Foram classificadas nessa categoria as opiniōes sobre competência, desempenho, postura e comportamento. Trata-se de uma questão comentada por todos os entrevistados, embora com menos registros do que o preconceito.

Muitas vezes eu vejo as meninas reclamando: meu sócio, meu chefe deu o caso do cliente mais legal, do cliente que paga, do caso mais legal pro cara e eu fiquei com o caso com o cara que não paga, o caso mais sofrido, entendeu? Então você ainda vê que os índices das mulheres, a grande maioria, são mais baixos do que o dos homens. Você olha o topo dos homens, você vê lá o deles sempre está melhor do que o das mulheres [Advogada-sócia, 36-40 anos, casada, com filho].

$\mathrm{Na}$ carreira em geral, mas com exceções, em escritórios onde a estrutura é maior, mais profissionalizada, uma pessoa estritamente técnica pode se tornar sócia. [...] Uma pessoa que tec- nicamente falando é excelente, mas que não tem um traquejo muito bom para negociação. Não é uma pessoa de business. Um exemplo é o advogado contencioso puro, é o advogado à moda antiga que não sabe falar com cliente, não sabe de finanças, ele só sabe atuar dentro do processo e falar com o juiz e com o promotor [Advogado associado, 31-35 anos, casado, sem filho].

Os escritórios grandes, na sua grande maioria, têm uma manicure fixa dentro do escritório, se faz cabelo, a mão. Porque para o escritório eles querem ter essa imagem perante terceiros, e, é claro, como é escritório grande, você tem lá cem advogados, é difícil controlar todo mundo mesmo, e as pessoas acabam abusando, essa coisa da moda, as pessoas, nem todo mundo sabe se portar. Por que se criou essa história do dress code? Bom, porque logo depois do verão, o sujeito vem com uma sainha e vem com uma rasteirinha. Será que isso é adequado? É um pouco de falta de desconfiômetro.

[Atuação difere] pela competência, eu não vendo imagem. Vendo resultado, não vendo imagem, esses escritórios vendem imagem e resultado. Então, sabe, tem algum sentido [Advogada-sócia de "boutique jurídica", 31-35 anos, casada, sem filho].

A performance e a postura ocupam lugar de destaque na identificação profissional e na construção da alteridade, em especial nas carreiras de maior prestígio social. Marcas que possam abalar esse status reforçam a neutralidade do profissionalismo no self. A passagem a seguir aborda a questão da "postura profissional neutra", na visão de um advogado gay:

[...] a questão do trejeito, de ser afeminado ou não, eu acho que isso implica uma postura de confiança que que o senso geral da sociedade tem; por exemplo, acho que você vai se sentir mais confortável sendo atendido por um profissional se ele mantém uma linha reta, não é pra ser o machão, grosseiro, aquele típico macho, entendeu, homem, e também não é pra ser uma pessoa que é homem e quer ser mulher enten- 
deu. Isso acaba criando um problema de confiabilidade no profissional, a pessoa acha meio estranho. Eu não tenho preconceito com isso, tanto faz, mas em geral as pessoas têm essa percepção. [...]

Pra parar com questão de preconceito acho que tem que parar de participar às pessoas se é gay, se é lésbica, se é isso ou aquele outro. Você não é nada, você é você, uma pessoa, um ser humano que trabalha. Pronto, ponto final [Advogado-sócio de renda, 26-30 anos, solteiro, sem filho].

O apagamento das marcas visíveis da diferença nessa passagem é acompanhado pela ênfase na identificação com a profissão que, neste caso, se sobrepõe ao pertencimento à comunidade homoafetiva. O profissionalismo repõe o status social negado às pessoas gays na sociedade e traz recompensas quando se reconhece a expertise possuída.

Rumens e Kerfoot (2009) analisaram homens gays no trabalho em organizaçôes receptivas à inclusão. Eles sugerem que mesmo nesses ambientes os gays atuam sobre o self para se identificarem como profissionais. Assim, eles não deixam de ser afetados pelas normas que tratam a sexualidade e $o$ profissionalismo como polos opostos.

As manifestaçōes sobre a performance profissional ocuparam uma posição relevante tanto entre advogados (segundo lugar entre os temas apontados) como entre juízes (terceiro lugar), mas ganharam significados distintos em cada uma dessas carreiras. As sociedades de advogados são reconhecidas por sua competência para os negócios, consultoria de excelência e imagem elitizada; em contrapartida a postura dos magistrados é marcada pelo reconhecimento social, pela autoridade e pela preocupação com a discrição.

A diversidade foi outro ponto que mobilizou a atenção dos entrevistados, com a ampla maioria se detendo em comentários sobre homossexualidade. O total de referências classificadas foi um pouco superior àquelas obtidas para as percepçóes de que $\mathrm{o}$ gênero faz diferença na carreira. A sexualidade ocupou o terceiro lugar e o gênero o quarto lugar nas respostas dos(as) advogados(as). O fato de a pesquisa ter entrevistado dois advogados que se identifica- ram como gays contrasta com a ausência desse tipo de relato entre os juízes, mas estes consideraram haver diversidade entre os pares, e o total de manifestaçōes discursivas sobre ela pontuou em primeiro lugar nas entrevistas da magistratura.

Exatamente, e fora que bem ou mal essa coisa de diversidade está pegando, está na moda, os escritórios lá fora têm, então por que a gente não pode ter também? Puxa vida, o cliente do escritório pediu a política de diversidade do escritório, porque é que não vai ter diversidade no escritório?. Será que não é um ponto de venda? Hoje em dia é tudo... né? Então se a gente conseguisse diferenciar de alguma forma e captar este cliente e ter a política de diversidade e trazer mais gente pro escritório está valendo, uai, né? [Advogada-sócia, 36-40 anos, casada, com filho].

Eu acho que no nosso caso muito pelo contrário, no Brasil a gente ainda está um passo atrás de sociedades, ou dos Estados americanos, ou da América do Norte, ou europeu, no sentido de... dos sócios realmente assumirem, eu sou abertamente gay. Acho que aqui a gente, os sócios são gays, mas ninguém faz promoção em cima disso, entendeu? A gente existe sim, o escritório fala inclusive na nossa web de propaganda que nós buscamos a diversidade e tal, tudo mais, todo mundo sabe, mas não existe, assim, um grupo de advogados gays aqui, interno. A gente não busca contratar advogados gays abertamente, apesar de isso ser uma política do escritório... [Advogado-sócio, 36-40 anos, solteiro, sem filho].

Embora algumas sociedades de advogados identifiquem potencial mercadológico na política de diversidade, atendendo a demandas de clientes empresarias e, em especial, de grandes sociedades estrangeiras com as quais desejam parcerias, a alternativa socialmente construída para a homossexualidade é ficar no armário no ambiente profissional.

Segundo Sedgwick (2007), o "armário" é uma característica fundamental na vida social, e não 
apenas para gays. $\mathrm{O}$ vínculo da heterossexualidade com o público e da homossexualidade com o privado é produzido no ambiente de trabalho ao impor-se a discrição ao gay e àqueles que sabem da sexualidade do colega.

As percepções sobre a diferença de gênero nas sociedades de advogados são mais vocalizadas do que na magistratura, sendo mencionadas por $93 \%$ dos advogados(as) dessas firmas e por $75 \%$ dos juízes(as), que deram mais ênfase ao fato de o gênero não explicar as diferenças na carreira. $\mathrm{O}$ fechamento generificado com estratificação e segmentação de enclaves femininos quanto à especialização (Bolton e Muzio, 2007) também é observado por profissionais nesses escritórios.

O direito de família é mais da mulher. Ele tem muito mais a ver com a mulher. [...] Porque o direito de família é psicologia. Assim, uma petição que você faz de direito de família tem duas frases de direito e trinta linhas de psicologia pura, e a mulher entende isso [Advogada associada, 21-25 anos, solteira, sem filho].

Eu acho que as mulheres acabam partindo mais para o consultivo, que é evitando o litígio [Advogado associado, 31-35 anos, casado, sem filho].

É mais comum o homem ter essa atividade de prospecção, é mais comum, até porque o homem usa muito o ambiente social para atividade de prospecção. Então é o futebol, é o happy hour, o ambiente dos amigos [Advogada-sócia, 31-35 anos, casada, sem filho].

Mesmo quando um grupo de advogadas de um grande escritório percebe a diferença de gênero como identidade e organiza uma comissão da mulher advogada, esse movimento ainda não se apresenta como transformação do enclave feminino em sedimentação generificada. Por enquanto, o uso que elas fazem do essencialismo de gênero visa um espaço de reconhecimento dessas diferenças na profissão.

Então a gente resolveu criar uma comissão [mulher advogada], foi em julho, pra criar essa comissão aqui dentro: "Oh o que vocês vão fazer? Clube do Bolinha, Clube da Luluzinha, que vocês estão fazendo, tramando?”. Assim, juro! A gente levou cada porrada que você pode imaginar, então aí a gente criou um fórum de discussão, e foi engraçado que pra gente vender pros sócios, pros homens, a gente resolveu criar uma estratégia, vamos falar que a gente tem dificuldades em lidar com números, captação de clientes, coisas do nosso dia a dia... [Advogada-sócia, 36-40 anos, casada, com filho].

\section{Conclusão}

Observamos na análise das entrevistas como os advogados e as advogadas atribuem significados às diferenças na carreira. Esse recorte mostrou-se fecundo para captar as formas híbridas de interseção entre os marcadores sociais e o profissionalismo no self. A perspectiva de uma identidade fixa e singular, seja profissional, de gênero ou de sexualidade, foi descartada, encontrando-se várias maneiras de se dar sentido às semelhanças e às diferenças.

Isto pode ser visto na escala de prioridade formada a partir das manifestações discursivas mais frequentes na advocacia. Os quatro temas que ocupam as primeiras posições nessa hierarquia foram os mesmos para advogadas e advogados. Todos deram maior ênfase ao preconceito, seguido da performance, da diversidade e da percepção de que o gênero faz diferença. A partir daí a escala se distingue entre eles e elas. Para as advogadas, a quinta posição refere-se à carreira e aos filhos; a sexta, aos custos emocionais da carreira, e a sétima, às questôes de progressão e gênero. Para os advogados, a quinta posição é a percepção de que o gênero não explica diferenças na vida profissional; e empatados em sexto lugar estão a negação de preconceito entre os pares, os custos emocionais e a questão da carreira e filhos.

Contrastando a magistratura com a advocacia, encontramos nesta última mais relatos sobre dificuldades na profissão, tais como os desafios para conciliar a vida privada, o trabalho e a atividade acadêmica, além das dificuldades em superar os 
obstáculos advindos da origem social da pessoa. Já entre os juízes(as), foram destacadas as dificuldades que a mobilidade espacial acarreta na vida familiar e a sobrecarga de trabalho. A progressão na magistratura envolve mudanças de comarcas e entrâncias do Poder Judiciário, tornando essa movimentação mais complicada para as mulheres que acumulam trabalho e cuidados com a família. O custo emocional que a carreira gera sobre a vida pessoal e social faz mais pressão sobre os magistrados do que sobre os advogados, mas a satisfação de juízes e juízas com a profissão é um pouco superior. Para estes, a diferença não se limita a marcadores sociais como gênero, sexualidade e raça. Ser magistrado(a) é, em si, uma diferença.

O contraste entre a atuação no setor privado e no setor público tem impacto sobre os discursos da diferença. Se nas narrativas de advogados e advogadas o preconceito desponta em primeiro lugar, nas entrevistas de juízes e juízas é a diversidade que sobressai. Para a advocacia, predomina a exclusão; para a magistratura, a inclusão. Os escritórios e sociedades de advogados produzem estratificação e segmentação generificada, acompanhadas de maior identificação de gênero, com incidência de respostas reconhecendo que ser mulher advogada faz diferença. No Judiciário, predomina a visão de que o gênero não faz diferença para o desempenho profissional, não produzindo enclaves femininos como na advocacia. $\mathrm{O}$ resultado tem sido uma menor percepção da diferença como identidade no que se refere ao gênero na magistratura. Nesse sentido, a hipótese do trabalho se confirma.

$\mathrm{O}$ enfoque que orientou esta pesquisa concebe a diferença a partir de uma variedade de discursos que a constroem, a contestam, a reproduzem e a ressignificam. As passagens extraídas das entrevistas revelam diferentes formas, por vezes contrárias, de lidar com a diferença, como vimos nas opiniōes a respeito do gênero. Outros relatos reproduziram diferenças ao reafirmá-las, como na essencialização do masculino e do feminino, constituindo enclaves generificados ou "preferências" de advogados e advogadas. Quanto aos excertos que ressignificavam a diferença, destaca-se a percepção de que ser magistrado já é em si uma marca da diferença.

\section{Notas}

1 Dados disponíveis em <www.oabsp.org.br>, consultado em 12/6/2012.

2 Sobre essa internacionalização na América Latina, ver Dezalay e Garth (2002).

3 Dados coletados no site do TJSP, <www.tj.sp.gov.br>, em 24/2/2011.

4 Cf. trabalho vinculado a esta pesquisa realizado por Barbisan (2011).

5 Comparadas às "lojas de departamentos", referindo-se às grandes sociedades de advogados.

6 No escritório em que ele trabalha, a equipe é hierarquizada em sócios de capital e sócios de renda, estes sem direito a voto, mas com participação nos rendimentos.

\section{BIBLIOGRAFIA}

ALMEIDA, Frederico N. R. (2010), A nobreza togada: as elites jurídicas e a política da justiça no Brasil. São Paulo, tese de doutorado, Programa de Pós-Graduação em Ciência Política da USP.

BARBALHO, Rennê Martins. (2008), A feminização das carreiras jurídicas e seus reflexos no profissionalismo. São Carlos, tese de doutorado, Programa de Pós-Graduação em Sociologia da UFSCar.

BARBISAN, Carolina. (2011), Profissionalismo e gênero na advocacia paulista. São Carlos, monografia de graduação em Ciências Sociais da UFSCar.

BECKER, Gary S. (1964), Human capital. Nova York, Columbia University Press.

BERGOGLIO, Maria Inés. (2007), "Llegar a sócia? La movilidad ocupacional em las grandes empresas jurídicas: análisis de gênero”. Centro de Investigaciones Jurídicas y Sociales. Argentina, Faculdad de Derecho, Universidad Nacional de Córdoba.

BOIGEOL, Anne. (2003), "The rise of lawyers in France", in Lawrence Friedman e Rogelio Pérez-Perdomo (eds.), Legal culture in the age of globalization: Latin America and Latin Europe, California, Stanford University Press.

BOLTON, Sharon C. \& MUZIO, Daniel. (2007), "Can't live without: gendered segmentation in the legal profession”. Sociology, 41 (1): 47-64. 
BONELLI, Maria da Gloria. (2011), "Profissionalismo, gênero e significados da diferença entre juízes e juízas estaduais e federais". Contemporânea, 1: 103-123.

BONELLI, Maria da Gloria; CUNHA, Luciana Gross; OLIVEIRA, Fabiana Luci \& SILVEIRA, Maria Natália B. (2008), ”Profissionalização por gênero em escritórios paulistas de advocacia”. Tempo Social, 20 (1): 265-290.

BRAH, Avtar. (2006), "Diferença, diversidade e diferenciação". Cadernos Pagu, 26: 329-376.

COMMITTEE ON WOMEN IN THE PROFESSION. (2006), "Best practice for the hiring, training, retention and advancement of women attorneys". Nova York, New York City Bar.

CONSULTOR JURÍDICO. (2007), "Brasil tem 1,9 milhão de bacharéis sem carteira da OAB". Disponível em <http://www.conjur.com. br/2007-jun-02/brasil_19_milhao_bachareis_ carteira>, consultado em 18/12/2011.

DAVIES, Celia. (1996), "The sociology of professions and the profession of gender". Sociology, 30 (4): 661-678.

DEZALAY, Yves \& GARTH, Bryant. (2002), The internationalization of palace wars: lawyers, economists, and the contest to transform Latin American states. Chicago, The University of Chicago Press.

EPSTEIN, Cynthia F.; SAUTÉ, Robert; OGLENSKY, Bonnie \& GEVER, Martha. (1995), "Glass ceilings and open doors: women's advancement in the legal profession". Fordham Law Review, 64: 291-449.

FEENAN, Dermot. (2009), "Editorial introduction: Women and judging”. Feminist Legal Studies, 17: 1-9.

FEUVRE, Nicky Le \& LAPEYERE, Nathalie. (2005), "Les 'scripts sexués' de carrière dans les professions juridiques en France". Knowledge, Work \& Society, 1, 3: 101-126, número organizado por Mirella Giannini (The feminization of the professions).

JUNQUEIRA, Eliane B. (1999), A profissionalização da mulher na advocacia. Rio de Janeiro, Fundação Carlos Chagas.

KAY, Fiona \& GORMAN, Elizabeth. (2008), "Women in the legal profession". Annual Review of Law and Social Sciences, 4: 299-332.
KAY, Fiona, \& HAGAN, John. (1995), "The persistent glass ceiling: gendered inequalities in the earnings of lawyers". British Journal of Sociology, 46 (2): 279-310.

MELO FILHO, Álvaro. (2011), "Selo OAB luta por uma educação que atenda o mercado". Disponível em <http://www.conjur.com. br/2011-nov-28/selo-oab-luta-prol-educacao-solida-base-humanistica2>, consultado em 18/12/2011.

MENKEL-MEADOW, Carrie. (1989), "Feminization of the legal profession: the comparative sociology of women lawyers", in R. Abel e P.S.C. Lewis (orgs.), Lawyers in society: comparative perspectives, Berkeley, University of California Press, vol. 3.

MOSSMAN, Mary J. (2003) "Engendering the legal profession: the education strategy", in Ulrike Schultz e Gisela Shaw (orgs.), Women in the world's legal professions, Oxford, Hart Publishing.

NELKEN, David \& FEEST, Johannes. (2001), Adapting legal cultures. Oxford, Hart Publishing.

ORDEM DOS ADVOGADOS DO BRASIL. (1996), Perfil dos advogados brasileiros. Brasília, Comissão de Ensino Jurídico, OAB.

RACKLEY, Erika. (2009), "Detailing judicial difference". Feminist Legal Studies, 17 (1): 11-26.

RHODE, Deborah L. (2001), The unfinished agenda: women in the legal profession. Chicago, American Bar Association, Committee on Women Professional.

RUMEENS, Nick \& KERFOOT, Deborah. (2009), "Gay men at work: (Re)constructing the self as professional”. Human Relations 62: 763-786.

SCHULTZ, Ulrike \& SHAW, Gisela (orgs). (2003), Women in the world's legal professions. Oxford, Hart Publishing.

SEDGWICK, Eve K. (2007), "Epistemologia do armário". Cadernos Pagu, 28: 19-54.

THORTON, Margaret. (1996), Dissonance and distrust: women in the legal profession. Melbourne, Oxford University Press. 


\section{PROFISSIONALISMO, DIFERENÇA E DIVERSIDADE NA ADVOCACIA E NA MAGISTRATURA PAULISTAS}

\section{Maria da Glória Bonelli}

Palavras-chave: Profissionalismo; Mundo do direito; Gênero; Diferença; Diversidade.

Em contraste com abordagens que enfatizam a identidade profissional construída a partir da semelhança, este artigo dá atenção à problemática da diferença entre profissionais do mundo do Direito, contrastando experiências e significados atribuídos por advogadas e advogados, juízas e juízes. Focaliza a interseção do profissionalismo com marcadores sociais, em especial o gênero e a sexualidade. A base de dados é a composição das sociedades de advogados e dos tribunais de justiça estadual e federal de São Paulo, a partir da qual se compara a estratificação por gênero nestas carreiras. Foram realizadas entrevistas qualitativas com 24 advogados, 18 juízes estaduais e 10 juízes federais, homens e mulheres, na capital e no interior paulista, que permitem classificar percepçôes de inclusão e diversidade ou de preconceito e discriminação.

\section{PROFESSIONALISM, DIFFERENCE AND DIVERSITY IN SAO PAULO'S ADVOCACY AND MAGISTRATURE}

\section{Maria da Glória Bonelli}

Keywords: Professionalism; Legal world; Gender; Difference; Diversity.

Instead of drawing attention to similarities among peers in the legal world, this study emphasizes how female and male lawyers and judges experience and attribute meaning to difference and diversity in their professional trajectory. It focuses on how professionalism intersects with social markers, especially gender and sexuality. The data collected shows the new organization of Sao Paulo law firms and the composition of the São Paulo State Court and the Federal Regional Court, which provides a comparative perspective on gender stratification of private and public legal practice. The research team interviewed 24 lawyers, 18 state judges and 10 federal court judges (women and men) providing material to support a classification of how lawyers and judges perceive inclusion and diversity or discrimination and prejudice in their careers.

\section{PROFESSIONNALISME, DIFFÉRENCE ET DIVERSITÉ DANS LA PROFESSION D'AVOCAT ET LA MAGISTRATURE PAULISTES}

\section{Maria da Glória Bonelli}

Mots-clés: Professionnalisme; Monde du droit; Genre; Différence; Diversité.

En contraste avec des abordages qui mettent en avant l'identité professionnelle construite à partir de la similitude, cet article analyse la problématique de la différence entre les professionnels du monde du Droit, en contrastant les expériences et les interprétations attribuées par les avocats et les juges, hommes et femmes. Il est centré sur l'intersection du professionnalisme avec des identifiants sociaux, en particulier le genre et la sexualité. La base de données est la composition des sociétés d'avocats et des Cour de justice de São Paulo, de l'État et fédérale, à partir desquelles nous avons comparé la stratification par genre dans ces carrières. Nous avons réalisé des entretiens qualitatifs avec 24 avocats, 18 juges de l'état et 10 juges fédéraux, hommes et femmes, dans la capitale et dans les villes de province de l'État de São Paulo, ce qui a permis de classer les perceptions d'inclusion et de diversité ainsi que de préjugé et de discrimination. 